\title{
Radar observations of ship-induced instabilities in the ocean-atmosphere system
}

\author{
Andre V. SMIRNOV \\ Cooperative Institute for Research in Environmental Sciences, University of Colorado/NOAA, Environmental \\ Technology Laboratory, 325 Broadway, Boulder, CO 80303, USA
}

(Received 6 January 1997, revised 29 August 1997, accepted 19 September 1997)

\begin{abstract}
Both natural and artificial (ship-induced) features of atmospheric motions can be seen in ocean radar imagery. Observations of a surface wake extending downstream from the atmospheric vortices in a thermal ship plume are described. To demonstrate the usefulness of radar systems in observing the ocean surface, we studied the behavior of hot ship exhaust, using a $2.25-\mathrm{cm}$-wavelength airborne radar. The ship-induced feature in the polarimetric radar images was observed in the ocean surface cold environment with moderate horizontal ambient winds. The smoke-like feature appears only in the vertically-polarized images, and not in the horizontally-polarized images. @ Elsevier, Paris / Ifremer / Cnrs / Ird
\end{abstract}

radar images / polarization / ship track / atmospheric vorticity / thermal plume

Résumé - Imagerie radar des instabilités induites par un navire. Les mouvements de l'atmosphère et leurs caractéristiques naturelles et artificielles (induites par un navire) peuvent être observés dans les images radar de l'océan. Le panache thermique d'un navire a été étudié à l'aide d'un radar aéroporté, à la longueur d'onde $2,25 \mathrm{~cm}$ : le sillage observé part de tourbillons atmosphériques et descend jusqu'à la surface de l'océan. L'effet du navire sur la polarisation des images a été étudié dans l'environnement froid de la surface océanique, par vents horizontaux modérés. Une caractéristique analogue à de la fumée n'apparât que dans les images polarisées verticalement et non pas dans les images polarisées horizontalement. ( ) Elsevier, Paris / Ifremer / Cnrs / Ird

imagerie radar / polarisation / sillage d'un navire / vorticité atmosphérique / panache thermique

\section{INTRODUCTION}

Atmospheric effects observed in cloud reflectivity downstream of ships have been attributed to the ships' aerosol plume [3]. In contrast with these aerosol effects, we observed a thermal effect in the atmosphere near the ocean surface. This thermal plume effect appears warm on infrared images and often has a distinct signature at night against the cool ocean background. We show that the instabilities introduced in the atmosphere near the ocean surface in the daytime can be seen in radar backscattering from the ocean surface.

Both natural and artificial (ship-induced) features of atmospheric motions can be seen in ocean radar imagery. To demonstrate the usefulness of radar systems in observing the ocean surface, we studied hot ship exhaust using the real-aperture radar (RAR) imagery performed during the 1992 Joint U.S.-Russia Internal Wave Remote Sensing Experiment, which took place from 12 to 25 July 1992 on the continental shelf off the east coast of the United States in the New York Bight region.

Active microwave measurements offer the best allweather observations of the ocean surface, since atmospheric effects are minimized. For the active techniques, the surface is illuminated by microwave radio waves. Each frequency is scattered by Bragg reflection from capillary waves. Regarding the imaging techniques, the backscattered power observed with a high-resolution single-frequency radar is plotted as a function of position on the surface. The RAR image, in general, does not reproduce exactly the visually imaged scene on the ocean surface. In this paper, which concerns microwave radar 
observations of the ocean surface, a ship-induced feature in the radar images has been identified as an atmospheric variability effect triggered by the hot ship exhaust.

It is well known that intense atmospheric vortices occur in the vicinity of large man-made and natural hot sources. The emission of hot gases by large engines produces a very warm and buoyant plume which, in a still environment, rises vertically. We are interested in the interaction of the plume with the environmental wind. In this case, the rising plume acts to produce loops in the otherwise horizontal vortex tubes present in the environmental wind field. Such effects occur most often in moderate to strong ambient flows of 4-8 $\mathrm{m} \mathrm{s}^{-1}[2,6]$. Because this type of plume produces two horizontal counter-rotating vortices, it is sometimes referred to as a "bifurcating" plume. This effect also produces a surface wake extending downstream from the plume [2]. Observations of a surface wake extending downstream from the atmospheric vortices in the thermal plume are described in next section.

\subsection{Observation of the surface wake of the atmo- spheric vortices in the vicinity of the ship thermal plume}

Details of the measurements are given elsewhere [8]. The results we present here emphasize the environmental measurements made during the experiment, which were affected by the fact that the R.V. Academik Ioffe, a $117-\mathrm{m}$ research vessel, of 6600 gross tons, with two $7000 \mathrm{HP}$ diesel engines, itself produced hot ship exhaust. It is also important to bear in mind that the Academik loffe operated in a "slow-speed" mode during the period of radar observations.

The airborne real-aperture radar (RAR on the Russian TU-134 aircraft) with a peak power of $60 \mathrm{~kW}$, a $2-\mathrm{kHz}$ pulse-repetition frequency, and a 110-ns transmitted pulse width, operated in the $K u$-band frequency $\lambda=$ $2.25 \mathrm{~cm}$ ). Each pulse at the $\mathrm{HH}$ (horizontal) polarization is followed by a pulse at the VV (vertical) polarization. The echoes from each transmitted pulse were square-law detected, log-amplified, and then digitized.

Each of the eight mapping flights conducted during the New York Bight experiment consisted of up to four swaths about $60 \mathrm{~km}$ in length, which were oriented to locate Academik Ioffe inside each image. The data obtained show distinct ship plume signatures, with local signal-to-noise ratios as large as $10 \mathrm{~dB}$ at VV-polarization; simultaneous HH-polarized images show no such features. (HH and VV are the horizontally and vertically transmitted and received components, perpendicular to the plane of incidence). Figure $I$ shows a pair of such imlages at the two polarizations. The distinct linear features of ocean internal waves are visible in both $\mathrm{HH}$ - and VV-polarized images, and especially the former. White "smoke-like" features are, however, seen only in VVpolarized images (the image in figure la shows this distinct wind-wave clutter region on the right-hand side of the R.V. Academik loffe). Also noticeable in figure $l b$ is the internal wave inside the "smoke-like" feature, where the radar contrast is greater than outside. Internal wave does not change the direction of propagation of this feature. The ship's smoke plume was also observed visually by the author from the aircraft as a grey shadow. The aircraft altitude was $2000 \mathrm{~m}$ and there were no clouds below it. The dark (turbulent) ocean wake behind the ship is obvious in images and seen as a "dark stem". Ship positions are shown in figure 2. Black dots on the map correspond to 10-min reckonings of position. The arrows between black dots show ship direction. The last black dot in the chain corresponds to time 15:20 UT ( $4 \mathrm{~h}$ difference with local time) and ship course $343^{\circ}$. The speed of the R.V. Academik Ioffe was 3-4 knots. Wind direction, as well as the direction of ship smoke propagation, taken from field observations, together with turbulent and surface wake of atmospheric effect derived from the radar images, are also presented in figure 2. The positions of the radar signature of the "smoke-like" feature for three different times are shown in figure 2 as closed-loop areas. The "smoke-like" feature from the VV-polarized image (figure $(b)$ corresponds to the upper closed-loop area in figure 2. One of the internal-wave radar signatures, and the aircraft flight direction, are also shown in figure 2.

During the flight, balloon-launched radiosondes were used to record atmospheric parameters from sea level to heights of $3-4 \mathrm{~km}$. In situ observations of wind $(\mathrm{H}=$ $20.6 \mathrm{~m}$ ) and atmospheric temperature profiles obtained from the R.V. showed a surface-based inversion up to $93 \mathrm{~m}$ with winds of $8.5 \mathrm{~m} \mathrm{~s}^{-1}$. In figure 3 curves 1 and 2 correspond to the time of observation (Universal Time (UT)) of the ship plume effect in the radar images of the ocean surface (high temperature values near the ocean surface (curves 1 and 2) can be related to the hot ship exhaust).

The key features of our radar images may be summarized as follows: (i) the "smoke-like" feature appears only in the VV-polarization but not in the HH-polarization; (ii) the contrast between the ship-effect feature and the ambient sea clutter is very large; (iii) the feature is very long, 
a

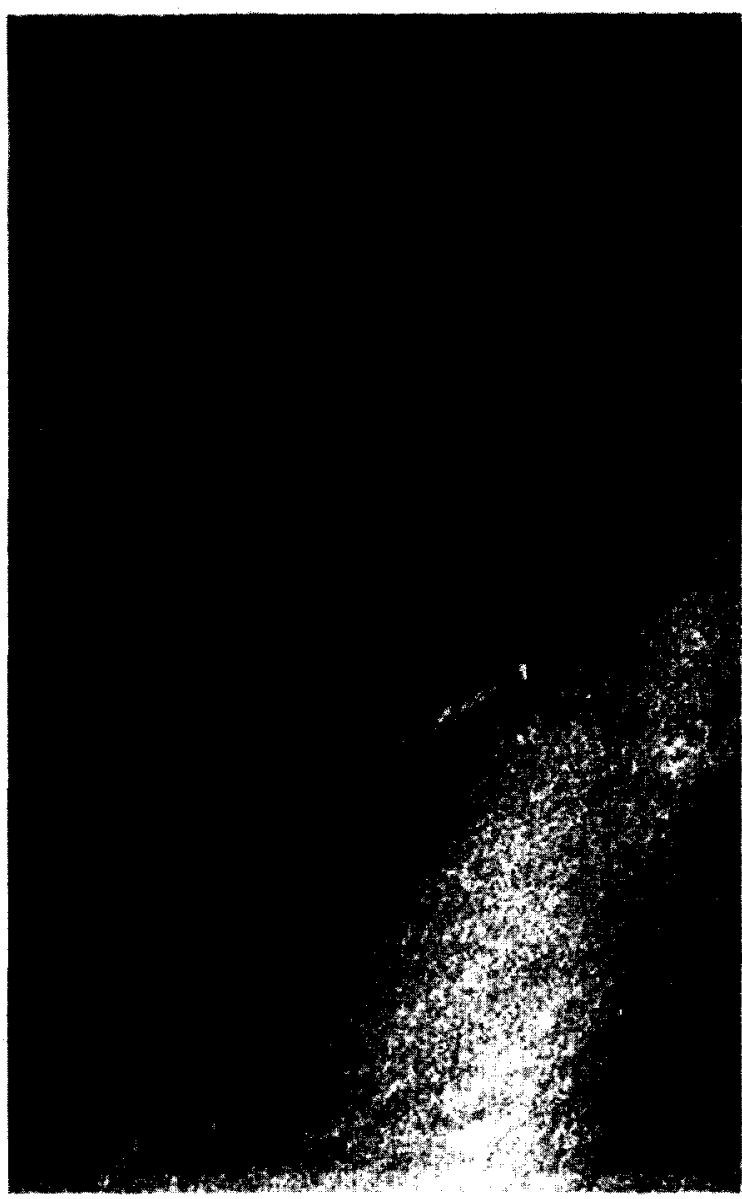

b

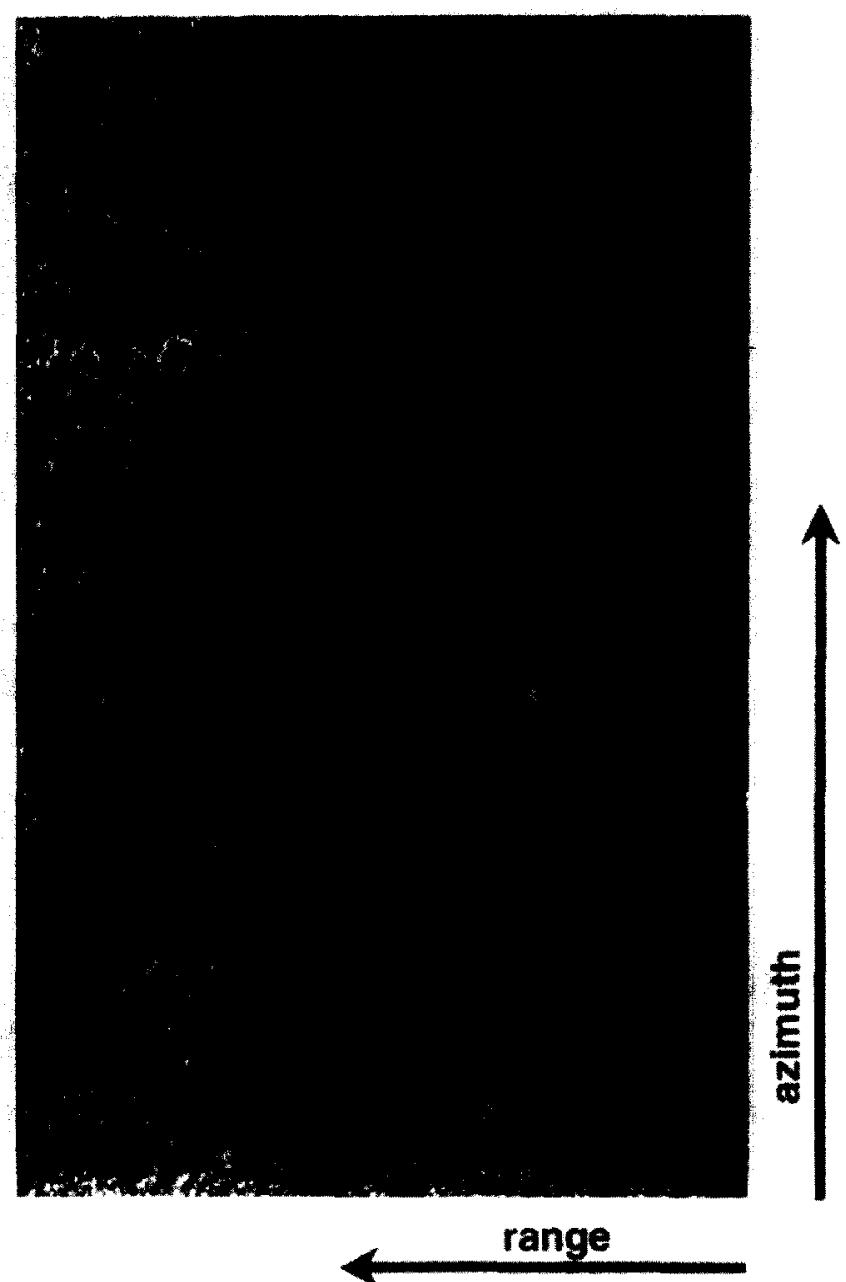

Figure 1. Radar images (VV-polarization (a), HH-polarization (b)) of the ocean surface obtained at 15:17 UT, aircraft course is $193^{\circ}$ on $18 \mathrm{July}$ 1992. Image scale is $12 \mathrm{~km}$ in range distance (horizontal axis) and $15 \mathrm{~km}$ in the azimuthal direction. The direction of radar illumination is from the left side of the images.

up to about $10 \mathrm{~km}$; (iv) the apparent angle between the wind direction and a surface anomaly feature is about $32^{\circ}$.

According to ship and wind speeds, the estimated angular difference between wind direction and smoke propagation in the atmosphere should be near $13^{\circ}$. The angle ( $\alpha-$ $\beta$ ) between the direction of ship smoke spread in the atmosphere and the position of the surface feature in the VV-polarized radar images is close to $19^{\circ}$ (table I).

\section{DISCUSSION}

The observation of the phenomena described in this paper was obtained at three different times on 18 July with too few ground truth data. Nevertheless, balloon measurements of air temperature are indicative of high temperature values near the ocean surface, because the balloon drifted into the ship's plume for a short time. Initially, a balloon has apparently lifted in down wind direction close to the warm plume due to wind drive. The difference between sea surface temperature and temperature at heights of about $30-50 \mathrm{~m}$ reaches $5{ }^{\circ} \mathrm{C}$. We assume that the ship-generated features represent thermal plumes causing complex atmospheric instabilities and smallscale vertical circulations in the marine atmospheric surface layer. It is expected that this cffect would be most dominant at slow ship speeds, since the thermal energy output per unit length of travel is greater at slower speeds. 


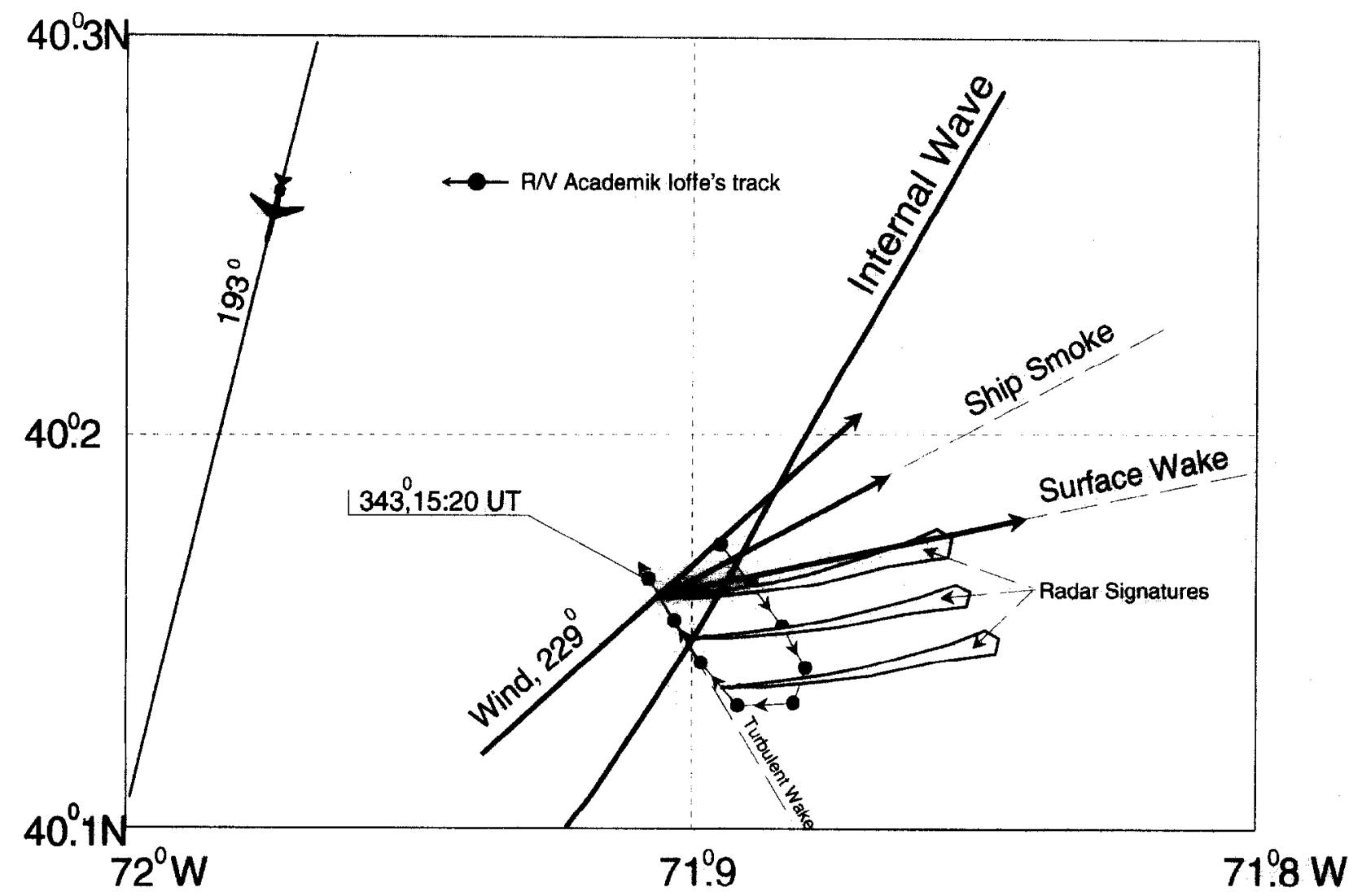

Figure 2. Illustration depicting the angles associated with radar observation of the surface wake of atmospheric vortices in the vicinity of the ship thermal plume. Angles are measured in the horizontal plane, relative to true north.

Table I. Navigational and environmental parameters of the experiment on 18 July 1992. Times given correspond to the radar observation of the ship. Abbreviations: Crs: course; Spd: speed; Dir: direction; ${ }^{\circ} \mathrm{T}$ : true azimuth; $\alpha$ : observed angle, angle between wind direction and surface anomaly of ship effect from radar images; $\beta$ : estimated angle, angle between wind direction and ship smoke in the MABL estimated based on information of ship and wind parameters. Wind-drifted smoke does not coincide with wind direction because of ship motion.

\begin{tabular}{|c|c|c|c|c|c|c|c|}
\hline $\begin{array}{c}\text { Time } \\
\text { UT } \\
\text { hh:min }\end{array}$ & $\begin{array}{c}\text { Aircraft } \\
\text { Crs } \\
{ }^{\circ} T\end{array}$ & $\begin{array}{l}\text { Ship } \\
\text { Crs } \\
{ }^{\circ} T\end{array}$ & $\begin{array}{l}\text { Ship } \\
\text { Spd } \\
m / s\end{array}$ & $\begin{array}{c}\text { Wind } \\
\text { Dir } \\
{ }^{\circ} T\end{array}$ & $\begin{array}{c}\text { Wind } \\
\text { Spd } \\
m / s\end{array}$ & $\begin{array}{c}\text { Observed } \\
\text { angle } \\
\alpha \text { (deg) }\end{array}$ & $\begin{array}{c}\text { Estimated } \\
\text { angle } \\
\beta \text { (deg) }\end{array}$ \\
\hline $14: 55$ & 193 & 340 & 2 & 232 & 9.7 & 32 & 10 \\
\hline $15: 08$ & 13 & 342 & 1.55 & 229 & 8.2 & 34 & 15 \\
\hline $15: 17$ & 193 & 343 & 2.01 & 229 & 7.8 & 30 & 14 \\
\hline
\end{tabular}

To our knowledge, the first experiments devoted to study of the dynamics of atmospheric vortices generated by man-made heat release were done by Dessens [4], who conducted a series of ground experiments specially intended to produce whirls and even tornados using a special array of burners. It was possible to vary the number of burners and thereby the calorific power. A total calorific output of some $200 \mathrm{MW}$ was achieved, and in this instance, artificial whirlwinds were initiated. Com- parison of our experiment with the observations of Dessens [4] and Church et al. [2], reveals the value of calorific power output to be the most obvious difference. (The rough estimation of ship power output is near $8 \mathrm{MW}$ ). It is possible, however, that the moderate horizontal wind which prevailed during our experiment was necessary for the generation of vortices of moderate intensity, and for the instability of the air layers near the sea surface. 


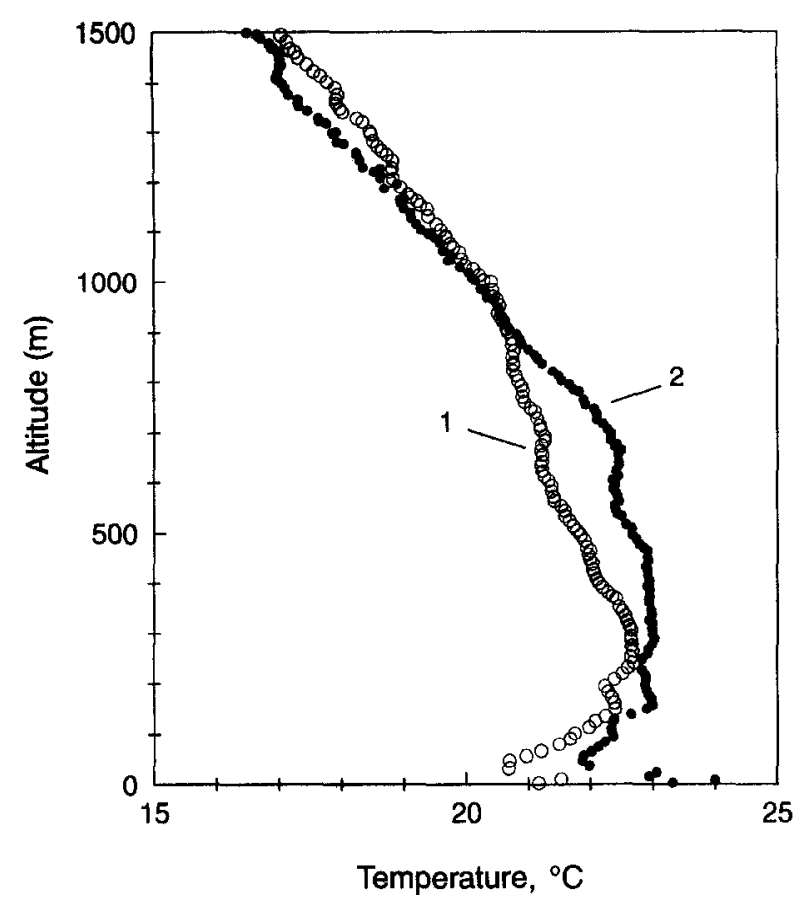

Figure 3. Measured vertical atmospheric profiles of temperature. Ship-induced radar clutter was observed on $18 \mathrm{July} 1992$ (see figure l): curve $1\left(12: 13 \mathrm{UT}, \mathrm{t}_{\mathrm{w}}=19.33^{\circ} \mathrm{C} ; \mathrm{t}_{\mathrm{w}}\right.$ is ship-measured sea surface temperature), curve $2\left(16: 30 \mathrm{UT}, \mathrm{t}_{\mathrm{w}}=20.36^{\circ} \mathrm{C}\right)$.

A hot ship plume affects the atmosphere by disturbing the ambient airflow and injecting heat above the ocean surface. According to Church et al. [2], the rising air in the plume is accelerated downwind so that the loop portion of each tube is carried downstream faster than the portion that does not enter the plume. These plumes consist of a pair of counter-rotating horizontal vortices on either side of the plume centre-line, and a sinking motion along the edges of the plume. Additionally, we suspect that hot ship plumes create a neutral or even unstable local atmosphere in the lowest $90 \mathrm{~m}$ above the water. However, the cold ocean surface re-establishes the inversion in a few minutes.

The most interesting feature is an angular difference $\left(\sim 9^{\circ}\right)$ observed between the direction of the surface wake of the plume in radar images and that which should result from combining ship speed and wind speed. This indicates that there is a time delay (in time series or space gap in imagery) between the change of the vertical temperature gradient through the ocean surface and surface fluxes response. Ambient wind shears are also very important in this process. Further numerical experiments may resolve this point.
Finally, a comparison may be made between our observation and the features noted in a forest fire, where vortices are well defined by smoke generated by the burning. Intense atmospheric vortices on or near such a fire have been observed by Doppler radar [1]. In this study, strong horizontal ambient winds were found to produce a bentover convection column, which was shown by the radar to have a strong horizontal flow at its edges and a weaker flow along the centre-line of the plume. The smoke plume produced by a strong, $13 \mathrm{~m} \mathrm{~s}^{-1}$ ambient flow was tracked by radar over a distance of more than $30 \mathrm{~km}$. In our experiment, we identified over $10 \mathrm{~km}$ the surface wake of the atmospheric vortices formed in the vicinity of the ship thermal plume, which was moderately wind driven. The smoke-like feature appears in the verticallypolarized images but not in the horizontally-polarized images, because the two polarizations are responding to quite different mechanisms. The radar backscatter in vertical polarization is produced mostly by Bragg scattering from ripples generated by local winds, whereas horizontally-polarized signals are more sensitive to breaking events. In our case, the plumes consist of horizontal vortices extended down to the sea surface on each flank, forming the outer edges of the surface wake of the plume in the ambient winds.

\section{CONCLUSION}

As published elsewhere, ship disturbances have been observed in two fields, and may be described as bodygenerated and wake-generated. The former are a consequence of the displacement of fluid by a solid object Kelvin wake and turbulent wakes as a result of ship motion on the surface [7], and include atmospheric disturbances resulting from the ship aerosol plume [3]. The classical ship wake on the ocean surface has been recently observed in synthetic aperture radar (SAR) imagery [5], despite the possible invisibility of the ship itself due to the characteristics of the SAR processor. But we are mostly interested in the second mechanism, involving wake-generated disturbances. In the present study, the atmospheric vortices triggered by ship thermal plume are found to change local wind stress, with the transformation of the spectrum of short ripples as a consequence. Perhaps for the first time, our observation of secondary effects offers a new insight into ship-generated disturbances in the ocean-atmosphere system. 


\section{Acknowledgments}

The experiment described here was conducted jointly by the DOD, JHU/APL, and the Moscow Space Research Institute of the Russian Academy of Sciences. The author wishes to pay special tribute to the enthusiasm for ocean remote sensing of the late Professor Valentin Etkin. S.F. Clifford is thanked for valuable discussions, and Joann Temple-Dennett for editorial comments. The project was supported by the joint NOAA/DOD-Advanced Sensor Applications Program.

\section{REFERENCES}

[1] Banta R.M., Oliver L.D., Holloway E.T., Kropfli R.A., Bartram B.W., Cupp R.E., Post M.J., Smoke-column observations from two forest fires using Doppler lidar and Doppler radar, J. Applied Meteor 31 (1992) 1328-1349.

[2] Church C.R., Show J.T., Dessens J., Intense atmospheric vortices associated with a $1000 \mathrm{MW}$ fire, Bull. Amer. Meteor. Soc. (1980) 682-694.

[3] Coakley J.A., Bernstein B.L., Durkee P.A., Effect of ship-stack effluents on cloud reflectivity, Science 237, (1987) 1020.

[4] Dessens J., Man-made tornadoes, Nature 193 (1962) 13.
[5] Liu A.K., Peng C.Y., Chang Y.-S., Mystery ship detected in SAR image, EOS Transactions, Amer. Geophys. Union 77 (1996) 17.

[6] McRae D.J., Flannigan M.D., Development of large vortices on prescribed fires, Can. J. For. Res. 20 (1990) 1878-1887.

[7] Munk W.K., Scully-Power P., Zachariasen F., Ships from space, Proc. Roy. Soc. London 412 (1987) 231.

[8] Smirnov A.V., Zavorotny V.U., Study of polarization differences in $K u$-band ocean radar imagery, J. Physical Oceanogr. 25 (1995) 2215. 